\title{
Valorização e Musealização do Património no Meio Urbano: Caso das Pinturas Murais Públicas da Cidade de Lisboa \\ M. Catarina Figueiredo ${ }^{1}$
}

\section{Resumo}

Importa compreender a função da museologia como um processo de transmissão de conhecimentos, heranças e memórias coletivas, premiando a comunicação. Nos dias de hoje, em plena globalização e com as novas tecnologias em expansão, coloca-se o desafio de adaptar as políticas e as práticas museológicas numa museologia interdisciplinar, compreendendo as valências das novas tecnologias de informação (TIC) a favor da Sociomuseologia.

Neste artigo, procura-se relacionar a museologia com o património mural, tendo por base a identificação prévia dos locais de pintura mural, bem como dos edifícios onde estas estão inseridas. Pretende-se analisar a sua história, os seus autores e arquitetos, encomendadores, e realizar um enquadramento sociocultural, que prevaleceu na Cidade de Lisboa (Portugal) durante o Estado Novo, com particular relevância histórica e museológica.

Proporcionar, um conhecimento pela arte mural, compreendendo o seu papel na sociedade de hoje e contextualizando-a à época em que foi executada. Interpretar a simbologia e a importância sociocultural que os murais tiveram durante o período do Estado Novo e que adquirem ainda hoje. Analisar o significado ideológico dos espaços públicos, percebendo o processo de espaço "sacralizado" ao "dessacralizado".

Importa então, vir a responder às seguintes perguntas de

1 Candidata ao Doutoramento em Museologia Universidade Lusófona, Lisboa. mcatarinavf@gmail.com 
investigação:

- Qual a importância de musealizar o património mural da Cidade de Lisboa?

- Que simbologias transportam as referidas pinturas murais?

- Qual o significado ideológico dos Espaços Públicos?

- Que vantagens trazem as novas tecnologias para a Museologia?

Palavras-chaves: Museologia e comunicação; Património; Pinturas Murais; Simbologia; Espaços Públicos.

\section{Summary}

Understanding the function of museology, as a process of transmission of knowledge, heritage and collective memories, rewarding communication. Today, in a constant process of globalization, with new technologies in expansion, the challenge of adapting policies and museological practices into interdisciplinary museology, comprising the valences of new information technologies (ICT) in favor of Sociomuseology.

In this article, one relates museology with mural heritage, based on first identifying the mural sites and buildings where they are located. One intends to analyze its history, authors and architects, commissioners, and the sociocultural environment that prevailed in the city of Lisbon (Portugal) during "Estado Novo", and with particular historical and museological relevance.

To provide knowledge for wall art and the understanding of its role in today's society, contextualizing it at the time it was executed. To interpret the symbolism and socio-cultural importance that the murals had at the time of "Estado Novo" and today. To analyze the ideological significance of public spaces and realize the "sacralized" the "desecrated" process space.

It is, therefore, important to provide answers to the following research questions:

- How important is to musealize the mural heritage of Lisbon?

- What symbols carry these murals? 
- What is the ideological significance of Public Spaces?

- What advantages can new technologies bring to Museology?

Keywords: Museology and communication; Heritage; Mural Paintings; Symbology; Public Spaces.

\section{Résumé}

Comprendre la fonction de la muséologie comme un processus de transmission des connaissances, le patrimoine et la mémoire collective, la communication enrichissante. Et aujourd'hui, en processus constant de la mondialisation avec les nouvelles technologies pour développer, mettre au défi d'adapter la politique et les pratiques muséologiques en muséologie interdisciplinaire, comprenant les valences des nouvelles technologies de information (TIC) en faveur de la Sociomuseology.

Dans cet article, nous rapportons la muséologie au patrimoine murale, notamment à base d'identifiant d'abord les sites de murales et les bâtiments où ils sont situés. Nous avons l'intention d'analyser son histoire, les auteurs et les architectes, commissaires et l'environnement socioculturel qui régnait dans la ville de Lisbonne (Portugal), au moment de l'Estado Novo et en particulier la pertinence historique et muséologique.

Fournir des connaissances pour l'art mural et comprendre son rôle dans la société d'aujourd'hui et de contextualiser au moment où il a été exécuté. Interpréter le symbolisme et l'importance socioculturelle que les peintures murales avaient à l'époque de l'Estado Novo et l'achat aujourd'hui. Analyser la signification idéologique des espaces publics et de réaliser l'espace de processus "sacralisée" au "profané".

Il est donc important de répondre aux questions de recherche suivantes:

- Quelle est l'importance de la muséalisation du patrimoine murale de Lisbonne?

- Quels symboles réaliser ces peintures murales? 
- Quelle est la signification idéologique des communes?

- Quels sont les avantages des nouvelles technologies apportent à la muséologie?

Mots-clés: La muséologie et la communication; Patrimoine; Peintures murales; Symbologie; Communes.

\section{A Problemática}

Ao longo dos tempos, a Museologia tem vindo a organizar-se, e consequentemente a produzir e apresentar um conjunto de documentos importantes para o processo de desenvolvimento museológico. Destacam-se, entre outras, as Declarações escritas por um conjunto de Organismos Internacionais, muito nomeadamente: a "Declaração de Santiago do Chile" (UNESCO/ICOM, 1972), a "Declaração de Québec" (ICOMOS, 1984), a "Declaração de Caracas" (UNESCO/ICOM, 1992), outros tantos documentos referente à Nova Museologia apresentados pelo $\mathrm{MINOM}^{2}$, assim como um conjunto de políticas de caráter museológico apresentadas pelo Conselho da Europa.

Além disso, diversos artigos, teses e assembleias têm tido um papel fundamental na transformação dos paradigmas dos (eco)museus e do seu papel na sociedade. Salienta-se, a nível nacional, a transformação dos museus portugueses ocorrida durante os anos 80 e 90, pautada por uma criação e crescimento dos núcleos museológicos ${ }^{3}$. Tendo sido um fato marcante o início do MINOM $^{4}$ em Portugal. Se outrora nos podíamos restringir a uma museologia tradicional de peças e coleções, este acontecimento veio despertar na nossa sociedade uma mudança sociocultural, e que olha o objeto museológico de uma forma muito mais completa.

De fato, e muito recorrentemente, grupos de especialistas definem

\footnotetext{
${ }^{2}$ Movimento Internacional para uma Nova Museologia

${ }^{3}$ Após o 25 de Abril de 1974, surgiram mais de 100 Museus em Portugal.

${ }^{4}$ Ver http://www.minom-portugal.org/
} 
o que é "relevante" em termos museológicos, bem como aquilo que deve ser esquecido e/ou preservado. No entanto, é inerente ao próprio ser humano a sua necessidade em conter memórias, bem como a sua ambição em ser importante e relembrado. Se somarmos a este fato que existe hoje em dia um "público" mais informado, menos ingénuo, e fortemente influenciado pela massa crítica, então cada vez mais é adotada pelas sociedades atuais a questão de se discutir o que é o "património".

De fato, cabe ao museólogo o difícil papel de criar um fio condutor entre o passado, o presente, e o futuro. Investigar e compreender aquilo que se deve preservar e o que se quer esquecer. Refletir ainda sobre o que é realmente relevante para a nossa civilização, tendo em conta que esta é muito díspar.

É dentro desta perspetiva, que importa então perceber a importância de se vir a musealizar o património mural da Cidade de Lisboa. Uma vez que, este reside no fato de ser na sua maioria desconhecido ou ignorado do público em geral, tanto na sua existência como na carga simbólica que transporta, pretende-se então com esta investigação realizar um contribuição para a museologia e que se baseia num outro olhar sobre o património mural da Cidade de Lisboa. Espera-se assim, poder contribuir para um maior envolvimento das comunidades naquilo que é o seu (re)conhecimento identitário e as suas memórias. Uma vez que os estudos e reflexões sobre o património mural da época são escassos, nomeadamente no que diz respeito à sua vertente Sociomuseológica, será provavelmente proporcionada uma intervenção na política cultural de um património esquecido e/ou incógnito. De fato, este estudo permitirá conhecer e clarificar o desempenho do poder que a pintura mural da Cidade de Lisboa obteve na época do Estado Novo ${ }^{5}$. Nomeadamente, compreender o contexto sociocultural das pinturas na época e nos dias de hoje.

\footnotetext{
${ }^{5}$ Estado Novo é o nome do regime político autoritário, que vigorou em Portugal durante 41 anos sem interrupção, desde a aprovação da Constituição de 1933 até ao seu derrube pela Revolução de 25 de abril de 1974. Período na sua maioria governado por António de Oliveira Salaza
} 
Pretende-se igualmente analisar o significado ideológico dos espaços públicos e perceber como estes se sacralizam e se dessacralizam ao longo dos tempos. Depreender qual o papel das relações políticas e como estas subjugaram a arte urbana. Perceber o que era considerado relevante, que referencias culturais importavam preservar, e como hoje esse património é trabalhado ao nível da memória coletiva. Importa ainda compreender de que forma se moldavam os problemas culturais, do património e da museologia. Por fim, realizar uma análise à simbologia dos murais e perceber a sua contribuição para uma nova conotação e do sentido ideológico do próprio edifício onde estão inseridas. Por último, importa compreender qual o impacto que obtiveram na sociedade da época e nos dias de hoje.

Considera-se real e importante a relação que a arquitetura estabelece com o ser humano, e que esta seja vista como uma obra de arte, monumento ou edifício. As alterações na reorganização espacial sempre tiveram impacto e prepósito na malha urbana. Causaram alterações tanto no quotidiano como nas memórias da comunidade. A título de exemplo, Lynch (2009) em "A Imagem da Cidade" expõe um estudo sobre três cidades norte americanas, onde reflete a preocupação e a necessidade dos habitantes em constituírem informação/imagens transmitidas pelo espaço urbano, por forma a conseguirem se situar no tempo e no espaço.

Ao recuarmos na história, verifica-se que desde o século XVI-XVII existiram transformações ideológicas dos espaços públicos. Refletindo uma conjuntura de mudança social, política e religiosa em Portugal e na Europa. Refira-se o exemplo dos diversos conventos que se transformam em escolas, hospitais e organismos estatais, alterando o seu propósito e ideologia inicial. O Professor e Arquiteto Ramos (2015, pp. 77-79) menciona ter existido na época do Estado Novo uma propaganda do regime para criar uma "imagem identitária de Portugal". Refere ainda e passo a citar:

"... desde 1929, a intervenção da Direç̧ão-Geral dos Edifícios e Monumentos Nacionais (DGEMN) na reconstrução de um património monumental em ruínas 
como parte do reforço do culto da Nação, onde o monumento, ao ser por todos compreendido, legitima o seu papel na singularização de uma identidade nacional. Assim, a acção da DGEMN sobre o edifício pode caracterizar-se como a transformação do edifício ou das ruínas dele num produto historicizável e de fácil consumo.

Ou seja, a legitimidade para as alterações arquitetónicas passam a conter uma "normalidade" inevitável para sociedade.

A título de exemplo refira-se o caso de estudo sobre a Assembleia da República, inserida no palácio de São Bento, sede do Parlamento desde 1834. O palácio inicia a sua história sendo o primeiro mosteiro beneditino fundado em Lisboa no ano de 1598. Surgem diversas alterações, quer a nível da tutela quer arquitetónicas. 0 Arquiteto Possidónio da Silva teve o encargo de acomodar o espaço religioso aos novos propósitos parlamentares. Em 1895, o palácio sofre um incêndio e o Arquiteto Ventura Terra recria o edifício, ampliando-o e alterando o seu índole conventual. Nos anos 40, o Arquiteto Pardal Monteiro constrói o salão nobre, no espaço da antiga igreja do Convento. O Pintor Adriano Sousa Lopes (18791944) projeta sete pinturas murais com o tema dos Descobrimentos Portugueses, embora tenha efetuado apenas um dos murais antes de morrer. Os pintores Domingos Ribeiro (18911975) e Joaquim Rebocho (1914-...) terminam as pinturas em 1945. A temática utilizada nas pinturas esteve em conformidade com a Exposição do Mundo Português de 1940.

Um outro exemplo de estudo de caso é o da Gare Marítima da Rocha de Conde de Óbidos e da Gare Marítima de Alcântara, projetadas em 1934 pelo Arquiteto Pardal Monteiro, mas que somente em 1938, Oliveira Salazar concede a sua ordem de construção. Ambas as gares ficaram concluídas em 1940, com pinturas murais da autoria de Almada Negreiros.

$\mathrm{Na}$ Gare Marítima de Alcântara, encontra-se um tríptico com a representação da lenda da Nau Catrineta, um outro representando a Cidade de Lisboa e a suas zonas ribeirinhas. Outro painel, isolado, 
com uma alegoria ao Portugal rural. Um outro painel, também isolado com a representação do milagre da praia da Nazaré. Na Gare Marítima da Rocha de Conde de Óbidos (ver Fig. 2) encontrase um tríptico com a temática alusiva aos trabalhos marítimos e portuários, à vida Lisboeta ribeirinha, e com a partida dos emigrantes, a contrastar, um imaginário de saltimbancos e arlequins de inspiração cubista. Na Gare Marítima da Rocha de Conde de Óbidos, embarcavam as tropas portuguesas para o Ultramar durante a Guerra Colonial, sendo esta restrita à companhia Colonial de Navegação.
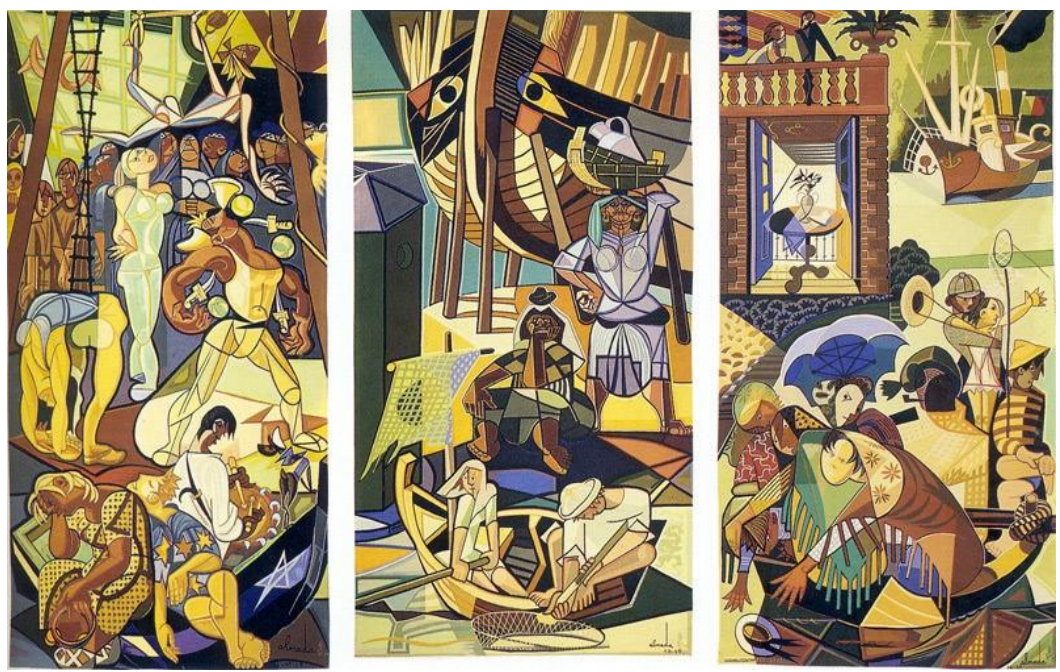

Fig. 2 - Exemplo do mural da Gare Marítima da Rocha de Conde de Óbidos.

Outro exemplo de estudo de caso - o Museu de Arte Popular criado em 1936, mas que sucessivamente foi abandonado, sem eletricidade, sem interesse político em prevalecer como núcleo museológico. Mais tarde, é reorganizado com o projeto do Arquiteto Jorge Segurado e inaugurado em 1948 com a presença de Oliveira Salazar e António Ferro. Voltou novamente a prevalecer o seu abandono e negligência. O museu abrangeu parte do conjunto de seis Pavilhões dedicados à temática da "Vida Popular", concebidos pelos arquitetos Veloso Reis Carmelo e João Simões, 
que em 1940 conteve a Exposição do Mundo Português. Encontrava-se distribuído por cinco salas: a sala de Entre Douro e Minho, a sala de Trás-os-Montes, a sala do Algarve, a sala das Beiras, e a sala da Estremadura e do Alentejo. O museu enriqueceu o próprio edifício com um conjunto expressivo e significativo de obras de arte, como pinturas murais e baixos-relevos de vários autores como Carlos Botelho (1899-1982), Eduardo Anahory (19171985), Estrela Faria (1910-1976), Manuel Lapa (1914-1979), Paulo Ferreira (1911-1999), Thomaz de Mello Tom (1906-1990). Reabre em 2009, pela ministra da Cultura Gabriela Canavilhas. O Museu, ao longo destes anos, tem vivido diversas vicissitudes, mesmo sendo classificado como Monumento de Interesse Público. Pode-se considerar o museu e o edifício que o contém, bem como as obras nele, um património relevante e de enorme memória coletiva.

Em relação aos diversos edifícios em estudo, estes foram organizados em quatro categorias: edifícios de ensino, lazer e cultura; particulares; religiosos; e estatais. Cada categoria está intrínseca a um público específico. Verifica-se que apenas determinada parte da população tem possibilidade económica e cultural em frequentar estes edifícios, sejam eles escolares ou de lazer. Aprender e conviver nesses edifícios, a nível arquitetónico e histórico, e de igual forma com as pinturas aí inseridas é um privilégio para determinada elite. Da mesma forma, o público que culturalmente tem formação religiosa é por norma quem frequenta os edifícios religiosos. Cada edifício, adquire assim um papel distinto no que concerne à transmissão das memórias e saberes na comunidade.

Existem diversas análises e investigações sobre o Estado Novo em Portugal, a título de exemplo refira-se Augusto França (1979), que menciona que a arte serviu como instrumento e alavanca para se considerar Portugal um país moderno. Segundo os autores Nunes (2003) e Cardoso (2013), a arte tem de se adaptar e corresponder às funções morais, dogmáticas e políticas. De fato, era da responsabilidade do artista disseminar o bom gosto, de forma a "instruir" a nobreza. Acciaiuoli (1998), refere que "A Exposição do 
Mundo Português" marca e determina os princípios impostos e aceites pelas artes produzidas e aplicadas em todo o território nacional.

Deve-se acima de tudo, conceber que a museologia é transversal entre as diversas ciências do conhecimento, tal como defende, entre outros Cardoso Pereira ${ }^{6}$. Entender-se que no trabalho em grupo com as diversas ciências a museologia pode enriquecer a todos os níveis. Poderá esta ser mais justa, criativa e inovadora. Existindo hoje uma panóplia de novas tecnologias ao nosso serviço e que nos ajudam a comunicar e a transmitir memórias, bem como conhecimento e saber, esta chegará desta forma a um público mais vasto. Deve-se ainda ter em conta que o trabalho em Grupo, em Rede, e em Comunidade é imprescindível para a sustentabilidade e a preservação da memória e do património.

Ao se equacionar o desenvolvimento de um museu virtual de pintura mural, recorde-se o quanto importante era para as comunidades o conhecimento real do seu património. Hoje, com todo o desenvolvimento tecnológico, é extremamente relevante proporcionar este serviço de virtual, para que as memórias possam chegar a um público mais vasto, sendo assim possível a sua preservação e musealização.

\section{Objetivos}

Este projeto de investigação tem como principal objetivo a realização de um estudo histórico e museológico das principais pinturas murais e decorações incisivas que decoram a via urbana da Cidade de Lisboa, bem como os edifícios onde estas se situam. É baseado na compreensão do papel politico na arte e como a simbologia das pinturas murais promoveram ou não, novas conotações aos edifícios e de que forma estes influenciaram a sociedade. Propõe-se a criação de uma estratégia de divulgação do património da Pintura Mural em Portugal e em particular da cidade de Lisboa. Pretende-se assim devolver ao público esse território, fomentando o serviço do "museu" e atuando desta forma como um

\footnotetext{
${ }^{6}$ Pedro Manuel Figueiredo Cardoso Pereira, Professor Doutor da ULHT de Lisboa.
} 
mecanismo de preservação do mesmo, muitas vezes esquecido ou ignorado. Embora cada obra se encontre acessível ao público, fruto de uma marca autoral ou do anonimato, a criação de um museu virtual permitirá causar um efeito de proximidade ao "visitante", promovendo desta forma o objeto museológico e mantendo-o sempre consciente do lugar de contexto dos frescos evocados. Através deste estudo, espera-se vir a realizar a criação de um museu virtual sobre o tema proposto. Refira-se a importância de se promover um diálogo e uma transmissão da mensagem/conhecimento pelo património mural através da utilização das novas tecnologias.

De forma a corresponder a um trabalho na área da SocioMuseologia, pretende-se promover o envolvimento das entidades detentoras das obras para criar um sistema de visitas (roteiro), face ao tipo de património apresentado, maioritariamente situado na via pública, e no entanto disperso pela Cidade de Lisboa (e.g. Assembleia da República, Gare Marítima de Alcântara, Faculdade de Letras da Universidade de Lisboa, Café Império, etc.). $O$ roteiro sobre pintura mural e decorações incisivas executadas entre os anos 30 e 60 do século passado, reunirá um enquadramento histórico e simbólico das obras, bem como a biografia dos artistas e o seu impacto social. Desta forma, será possível proporcionar às entidades uma corresponsabilização, onde a Sociomuseologia consistirá num papel participativo e inclusivo das comunidades locais.

\section{Estado da Arte}

\subsection{A Importância da Pintura Mural em Portugal}

Um conjunto de vários autores no panorama da história de arte nacional tem vindo a debruçar-se sobre o estudo da Pintura Mural. Desta forma, os seus contributos para o valor patrimonial são inequívoco, bem como o potencial de investigação associado a nível autoral (escolas de pintura), plástico e social (Serrão, 1992; Bessa, 2007; Gonçalves, 2008, Afonso, 2009; Caetano, 2010; Monteiro, 2013; Cardoso, 2013). Dentro destes contributos, que revelam 
também conhecimentos importantes para a Museologia, refira-se o trabalho de Gonçalves ${ }^{7}$ (2008), e que desenvolveu a criação de um projeto de revitalização patrimonial denominado de "Rota do Fresco" (em 1998). Teve como principal objetivo promover visitas ao património cultural desconhecido ou inacessível da pintura mural a fresco no Alentejo, possibilitando desta forma a sua (re) descoberta, através de visitas para grupos, individuais ou de empresas.

Um outro contributo relevante foi a abertura de um novo espaço museológico em Monsaraz, intitulado "Monsaraz Museu Aberto". O Museu do Fresco contém um fresco do século XV alusivo à justiça terrena e justiça celeste, "Fresco do Bom e Mau Juiz" único na Europa. A Camara municipal de Reguengos de Monsaraz encontrase empenhada na divulgação deste património, bem como na colaboração com a rota do fresco já existente no conselho. Consideram ainda aceder as novas tecnologias de modo a que o visitante possa usufruir de todas as potencialidades da região ${ }^{8}$. É dentro desta perspetiva e na ausência de estudos mais profundos sobre as Pinturas Murais Públicas na Cidade de Lisboa entre a década de 1930/60, que se pretende enquadrar o presente trabalho de investigação, salientando ainda a importância do estudo para a valorização e musealização do património no meio urbano. Refirase para tal Cardoso ${ }^{9}$

"Estou a ver o quê? Como, dentro de mim, e por que parte de mim, estou a vê-lo? O que é que sempre vi do que estou a

\footnotetext{
${ }^{7}$ Gonçalves foi coordenadora deste serviço até 2008, ao serviço da Associação de Municípios do Alentejo Central (Cuba). Em 2007, fundou a Spira - Empresa de revitalização patrimonial, onde exerce funções como Directora-geral. Foi membro do Conselho Consultivo do ICOMOS Portugal (2007-2008). Em 2010 recebe a Menção Honrosa prémio "Inovação" Turismo do Alentejo, Finalista Categoria "Serviços" Prémios Turismo de Portugal 6a edição; Declaração de Interesse para o Turismo para o projecto Rota do Fresco.

8 www.cm-reguengos-monsaraz.pt.

9 Cardoso, P. (2011). A Cultura perante o Património. Trabalho de PósDoutoramento.
} 
ver, e o que poderei ainda não ter visto? O que é que esse ver não me deixou ver? Qual é a responsabilidade na comunicação que se faz dele à comunidade?"

As reflexões do autor espelham a forma como cada individuo interpreta e processa a transmissão de uma determinada mensagem, tornando-a desta forma tão pessoal e única. De facto, a transmissão do conhecimento realizada através da comunicação entre o objeto e o ser humano, reflete a forma como este pode ser reproduzido no passado, presente e futuro nas memórias de cada individuo, por outras palavras, o pilar da museologia.

\subsection{A importância das novas tecnologias na Museologia}

Temos hoje ao nosso dispor uma quantidade considerável de possibilidades para divulgar e comunicar num curto espaço de tempo, com a capacidade de conter uma globalidade antes inatingível. Estamos perante o mundo das novas tecnologias e da internet, subsistindo ainda um longo caminho a percorrer. Existe ainda um público que não tem acesso às novas Tecnologias de Informação e Comunicação (TIC). As (TIC) estão ao dispor da sociedade e da museologia e têm originado alterações significativas no molde de pensar e de atuar de cada pessoa. Este assunto tem sido abordado e estudado por Moutinho (1992), de Varine (1992), Castells (2002), entre outros autores de relevo para o espectro museológico.

Moutinho (1992) referiu que a transformação da sociedade levou a uma mudança no modo de pensar a Nova Museologia. O autor de Varine (1992) salienta uma museologia inovadora, onde menciona a importância do trabalho do museólogo com a comunidade, como forma de sustentabilidade para o desenvolvimento da cultura futurista. Ainda, segundo Castells (2002), os efeitos das TIC na forma de pensar e atuar de cada pessoa são inquestionáveis. O ser humano recebe, entende e explora a informação de forma díspar, reagindo ao trabalho em rede de forma ímpar, consoante a sua idade, instrução e localização espacial. Já Galdo \& Nielsen (1996) partilhavam desta tese. 
As pinturas que se pretendem vir a estudar encontram-se sem qualquer tipo de informação a seu lado. Desta forma, a transmissão da mensagem é débil ou mesmo inexistente. A utilização das (TIC) permitirá, entre outros aspetos, aceder a este património e recolher informação valiosa sobre o mesmo (e.g. enquadramento histórico e simbólico, bibliografia dos artistas, etc.).

A visita virtual permite ao visitante uma participação cognitiva criatividade - acrescentada ao objeto musealizado, tal como referem Perlin (2000) e Muchacho (2005). Propõem-se assim criar um diálogo entre as pinturas murais e seus autores, tais como Almada Negreiros (1893-1970), Luís Dourdil (1914-89), Sousa Lopes (1879-1944), Domingos Rebelo (18911975), e Joaquim Rebocho (1912-), e os arquitetos Pardal Monteiro (1897-1957), Jorge Segurado (1913 - 1988) e Raul Lino (1879-1974), transmitindo conhecimento nas conceções das pinturas e o contexto histórico em que foram realizadas (Regime Salazarista, Estado Novo).

\subsection{Realidade Aumentada (RA)}

A "Realidade Aumentada" (RA), que surge com o desenvolvimento das novas tecnologias é considerada viável e de potencial elevado para a museologia, tal como referem Haguenauer et al. (2008), Silveira (2011), e Reis \& Barbosa (2014). Não só a nível didático e educativo, mas também a nível da preservação de peças/acervos. Uma peça que se encontre debilitada a nível da sua conservação, e não possa estar à vista do público, ou ser exposta numa exposição, encontra precioso auxílio na RA. Desta forma, o objetivo museológico de preservação e a sua comunicação pode ser eficazmente assegurado. Com a RA, é possível, por exemplo criar-se um filme ou uma imagem virtual a $3 D$ da peça. Além de ser colocada em 'exposição', esta continua a prestar o seu papel de transmissão de memória e de conhecimento. A sua perspetiva tridimensional, aliada a um movimento rotacional, torna esta mais aliciante e interativa (Mello, 2012) ${ }^{9}$.

A título de exemplo, é possível visualizar novas perspetivas da cidade de Lisboa através da utilização da RA. A empresa "App 
Rewind Cities"10 Apresenta-nos através de dispositivos móveis (smartphones, tablets, etc.) um conjunto de imagens e vídeos de locais da cidade, sendo desta forma possível observar acontecimentos históricos, contextualizando-os. É possível sobreporem-se imagens, de acordo com a criatividade de cada utilizador, podendo

Janaina Cardoso de Mello, em Projetos Museologia UFS,
revista Museitec, diversos projetos como ("Mnemosine
Digital Banco de Dados sobre Museologia e Património
$2010-2011$, e "Véritas Mouseion Dicionário Electrónico de
Termos Museológicos (2011-2012) e "Sistemas de
Informação museológica, cyber cultura e digitalização do
patrimônio sergipano" (2010-2012), e "Laranjeiras Doc-
Digital: Produção de Guia e Catálogo Digitais da
Documentação do Arquivo Público Municipal de
Laranjeiras" (2012), e "Véritas Mouseion 3D Acervos
Expositivos com rotação em 360 para um dicionário
eletrônico de termos museológicos" (2012-2013), e "Véritas
Mouseion: Topografia Digital dos Museus de Sergipe"
(2013). ${ }^{10}$

este se situar em ambientes diversos. Com a RA o mundo real fica mais próximo de nós. Ao serem adicionadas diversos tipos de informação, tais como gráficos, sons, e sensações táteis, a mensagem transmitida amplia-se e diversifica-se. Assim, a forma como vemos o mundo e como o podemos mostrar a quem nos visita está a sofrer alterações.

\subsection{Códigos Quick Response (QR)}

O trabalho realizado por Zuarte (2011) é um bom exemplo de aplicação das novas tecnologias na Museologia, mais

\footnotetext{
${ }^{10} \mathrm{http}: / /$ www.rewindcitieslisbon.com/apresentacao-da-app-rewind-cities/
} 
concretamente, a utilização de códigos Quick Response (QR). Tratando-se de um código bidimensional, o QR pode guardar ainda mais informação do que o tradicional código de barras e que é unidimensional. Com a ajuda de um gadget, câmara ou scâner, o código é convertido em texto, permitindo desta forma que todo tipo de utilizadores acessão à informação disponibilizada (e.g. indivíduos portadores de deficiência visual). Zuarte (2011) considerou ainda desenvolver a possibilidade de incluir todos os utilizadores na dinâmica dos jogos virtuais. Com a intenção de auxiliar os portadores de deficiência na interação e aprendizagem através de jogos tradicionais interativos adaptados para plataformas digitais, como o exemplo dos jogos com suporte em LGP (Língua Gestual Portuguesa) e áudio descrição e legendagem.

\subsection{Museus Virtuais}

Os primeiros sites museológicos surgiram na década de 90 . Todo o trabalho de investigação dos profissionais dos museus, bem como a sua apreensão das possibilidades e usabilidade dos museus "virtuais", é contudo recente. A Internet veio revolucionar os processos museológicos, permitindo a estes trabalhar com referências patrimoniais digitais, preferencialmente dispostos em rede e que alteram desta forma a noção de tempo e de espaço museológico. O assunto foi estudado por Thompson (1998), Guareschi (2000) e Silva (2002), e que concluíram que as novas tecnologias de informação e a internet vieram alterar o nosso modo de comunicar enquanto museólogos e consequentemente transmitir conhecimento a um público vasto e heterogéneo.Com a Internet o museu passou a estar sempre aberto (e a qualquer hora), sem "nunca" encerrar.

Os museus virtuais permitem-nos repensar também os públicosalvo. Diversos investigadores tais como Day \& Evers (1997), Galdo \& Nielsen (1996), Moutinho $(1992,2007)$ e de Varine (1992) refletem na utilidade de um trabalho interdisciplinar ao nível do pessoal interno e externo ao museu, e da compreensão diversos graus de comunicação que existem. $O$ benefício do conhecimento oriundo 
das competências do marketing. Procura-se um museu virtual apelativo e que contenha informação sucinta e clara, uma vez que, a informação em excesso pode provocar o desânimo e o seu abandono. De certa forma, os museus virtuais são vistos como um complemento ao museu físico, ainda que os itinerários e percursos sejam por eles escolhidos ou propostos. A comunicação é direcionada para captar um público para uma visita física, oferecendo informação extra, e que pode ocorrer anteriormente ou posteriormente à visita física.

Como referiu Perlin (2000), Muchacho (2005), Oliveira \& Silva (2007), o museu virtual disfruta de um diálogo com um público sem fronteiras, ativo e multidisciplinar, oferecendo-lhe inúmeras possibilidades de interagir com a coleção/acervo, através das suas visitas virtuais. Trata-se de uma experiência pessoal que acrescenta ao objeto musealizado uma participação cognitiva bem como a criatividade do visitante, proporcionando um enriquecimento amplo, despertando desta forma a curiosidade para a visita física, acrescendo uma maior noção de património e de como é importante este ser preservado.

Ao realizarmos uma pesquisa eletrónica, apercebemo-nos que grande parte dos museus virtuais consiste num site e que serve de folheto eletrónico do mesmo, incluindo a sua própria apresentação. O visitante tem acesso à sua história, aos seus horários de funcionamento e aos seus programas. É ainda possível visitar determinadas exposições temporárias e que já não se encontrem no seu espaço físico, bem como a disponibilização de bases de dados dos acervos do museu, fazendo da internet uma espécie de reserva técnica das exposições. Estes museus reúnem em conjunto memória, história, cultura, e preservação, podendo proporcionar visitas lúdicas e interativas a diversos tipos de públicos, potenciando o turismo e a comunicação com a sociedade e com o mundo. Atualmente, e com as novas tecnologias, encontramos uma panóplia de "brinquedos" ao nosso dispor. Só na Cidade de Lisboa, com a ajuda de Smartphones ou Tablets e em conformidade com o Google, é possível retirar partido da RA, criando assim um novo 
conceito de guia turístico. É-nos possível aceder à informação ao minuto com acesso a mapas, a eventos culturais, gastronómicos, entre outros.

Como anteriormente referenciado, vários foram os contributos ao longo dos últimos 70 anos para o desenvolvimento e instrução de uma nova museologia. Desde os contributos das declarações da Unesco (1972) - "Museu ao Serviço da Comunidade" e de Québec (1984) - "Museu como função social e o carácter global das suas intervenções", passando pelos contributos do Museólogo George Henri Rivière (1897- 1985) e que se debruçou sobre a necessidade de existir uma inovação das práticas museológicas. George HenriRivière e André Desvalles partilham ainda a ideia de uma Museologia como facilitador do processo de diálogo, tal como Paulo Freire (1921-1997), Peter Van Mensch (1947 -...) e Mário Moutinho (1990, 1992, 1993, 2002).

\section{4 - Metodologia}

No que concerne à metodologia, esta deverá assentar em etapas sequenciais que resultem numa síntese lógica, onde o processo abarque uma rotatividade pelas diversas problemáticas em estudo. Criando desta forma uma organização entre a teoria e os dados empíricos obtidos. O modelo teórico-concetual articula com a Sociomuseologia, os Espaços Públicos e o Património, tendo por base o estudo das pinturas murais da Cidade de Lisboa (ver Fig. 1). No que concerne ao estudo analítico, será disposto por quatro parte, sendo o primeiro o estudo e análise do significado ideológico dos espaços públicos, o segundo os murais nos espaços públicos, o terceiro a análise do espaço sacralizado ao dessacralizado, e por fim a pintura mural do Estado Novo na Cidade de Lisboa. 

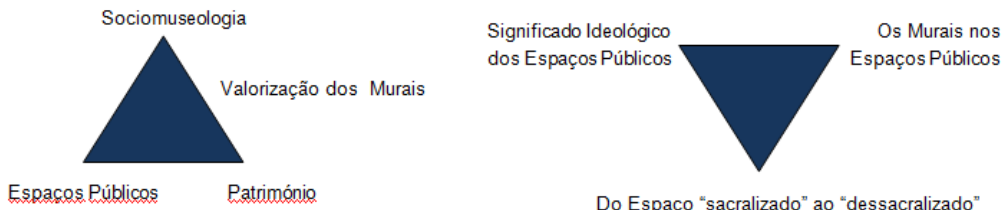

Fig. 2 - Modelo metodológico

Procura-se compreender como as diversas áreas do saber podem contribuir numa sociedade atual e global e quais as vantagens na preservação das memórias coletivas. A nova museologia defende que o papel do museu não se centraliza dentro deste e que deve extravasar e difundir-se na comunidade, de forma a permitir uma comunicação alargada a todos, entre o presente e o passado, premiando as memórias coletivas - o Património.

A metodologia balançará ente a pesquisa qualitativa, centralizada no levantamento bibliográfico, entrevistas e pesquisa bibliográfica de forma a dar consistência ao estudo de caso. Na pesquisa quantitativa, no que diz respeito ao trabalho de campo, que se estende em verificar a viabilidade do envolvimento das entidades detentoras das obras para a elaboração de visitas (roteiro) de forma a perceber como se situam as instituições no quadro prático Sociomuseológico.

\section{5 - Do Modelo Concetual ao Analítico}

No que concerne o estudo analítico, este será disposto em quatro partes. A primeira parte, corresponderá ao estudo e análise do significado ideológico dos espaços públicos. A segunda, focará os murais nos espaços públicos. A terceira, realizará uma análise do espaço sacralizado e do espaço dessacralizado. Na quarta parte, realizar-se-á o caso de estudo sobre a pintura mural do Estado Novo na Cidade de Lisboa. Resumidamente: 
1. Significado ideológico dos espaços públicos: pretende-se compreender a problemática envolvente ao conceito de espaço público; e compreender desta forma a extensão e o molde da apropriação a nível político, com o desígnio de entender como se instituía o espaço do cidadão.

2. Murais nos espaços públicos: perceber a problemática envolvente à deliberação das pinturas murais no espaço público e verificar de que forma auferiu significado perante a sociedade. Importa ainda perceber como influenciaram e conotaram os espaços públicos e a sua comunidade.

3. Do espaço sacralizado ao dessacralizado: neste parte importa abordar a problemática e o processo de sacralização e dessacralização dos espaços públicos, Entender como o poder político e a alteração do gosto interferiram no processo identitário e nas alterações culturais dos espaços públicos.

4. A pintura mural do estado novo na Cidade de Lisboa - caso de estudo: Aqui, pretende-se estudar e analisar as pinturas murais e incisões decorativas, tendo por base a identificação prévia dos locais de pintura mural, bem como os edifícios onde estas estão inseridas. Abordar a sua história, autores, arquitetos, encomendadores e enquadramento sociocultural.

E, ao nível dos Edifícios a estudar:

- Edifícios com relevância patrimonial e museológica, elencados por Edifícios de Educação (Escola Luísa de Gusmão, Escola Padre António Vieira, Escola Patrício

Prazeres, Escola Primária na calçada da Boa Hora, Faculdade de Direito da Universidade de Lisboa, Faculdade de Letras da Universidade de Lisboa, Faculdade de Medicina de Lisboa, Reitoria da Universidade de Lisboa).

- Edifícios de Lazer e Cultura (Antigo Cinema de Alvalade, Antigo Cinema Império, Antigo Cinema Paris, Café Império, Biblioteca Nacional de Lisboa, Museu da Farmácia, Museu de Arte Popular, Restaurante Panorâmico de Monsanto). 
- Edifícios "Particulares" (Edifício Bloco Águas Livres, Prédios no 158, 160 da Avenida do Brasil).

- Edifícios Religiosos (Igreja Nossa Senhora de Fátima, Igreja São João de Brito, Igreja São João de Deus, Igreja do Santo Contestável).

- Organismos Estatais (Assembleia da República, Casa da Moeda, Casa do Militar da Armada, Diário de Noticias, Gare Marítima da Rocha de conde Óbidos, Gare Marítima de Alcântara, Instituto Português de Oncologia, Ministério das Finanças).

\section{6 - Conclusões}

É importante compreender a função da museologia como um processo de transmissão de conhecimentos, heranças e memórias coletivas, onde se deve valorizar a comunicação. Interpretar, em pleno século XXI, onde cada "minuto" se transforma num novo paradigma da globalização e das novas possibilidades tecnológicas. Tecnologias essas, que alteram mentalidades, criando assim novas valências e que podem e devem ser utilizadas a favor da Sociomuseologia. Considero desta forma, que a utilização das diversas ferramentas (tecnológicas), podem melhorar a comunicação, proporcionando a transmissão da mensagem a um maior número de pessoas/público.

A questão de como a museologia se conjuga com o património mural, reside no facto desta arte conter uma simbologia carregada, com uma historicidade e uma carga identitária importante e valiosa. Pretende-se com este estudo, compreender o papel sociocultural que os murais tiveram na época do Estado Novo e que adquirem ainda hoje, dando a conhecer as diversas alterações ideológicas que auferiram os edifícios. Compreendendo então, as valências deste património mural, ressalvo assim a importância deste projeto, em musealizar as pinturas murais e as incisões decorativas da cidade de Lisboa. Desta forma, as memórias que este acarreta, tanto a nível histórico como sociocultural, podem vir a ser conhecidas e compreendidas pela sociedade. 


\section{Referências}

Acciaiuoli, M. (1998). Exposição do Estado Novo:1934 - 1940. Lisboa: Livro Horizonte.

Afonso, L. (2009). A Pintura Mural Portuguesa entre o Gótico Internacional e o fim do Renascimento:

Formas, Significados, Funções. Lisboa: Fundação Calouste Gulbenkian.

Bessa, P. (2007). Pintura Mural do Fim da Idade Média e do Início da Idade Moderna no Norte de Portugal.

Tese Doutoramento, Universidade do Minho, Instituto de Ciências Sociais.

Brandão, C. R. (1983). Pesquisa Participante. São Paulo: III edição Brasiliense.

Caetano, J. (2010). Motivos Decorativos de Estampilha na Pintura a Fresco dos Séculos XV e XVI, no Norte de Portugal. Relações entre Pintura Mural e de Cavalete. Lisboa: Universidade de Lisboa.

Cardoso, P. (2011). A Cultura perante o Património. Trabalho de PósDoutoramento.

Cardoso, S. (2013). Pintura Mural na Cidade do Porto no Estado Novo. Porto: Mestrado na Faculdade de Letras da Universidade do Porto.

Carneiri, A. M. (2004). O Património reencontrado - centro Histórico de Guimarães, património da humanidade: a cidade enquanto memória, espaço de identidade e cidadania. Universidade do Minho: Tese de Mestrado.

Carneiro, A. M. (2004). O património reencontrado - Centro Histórico de Guimarães, património da humanidade: a cidade enquanto memória, espaço de identidade $e$ cidadania. Tese de Mestrado:

Universidade do Minho.

Castells, M. (2002). A Era da Informação: Economia, Sociedade e Cultura. Lisboa: Fundação Calouste Gulbenkian.

Day, D., \& Evers, V. (The Role of Culture in Interface Acceptance). 
1997. Lisboa: Interact.

de Varine, H. (1992). As raízes do futuro: o património a serviço do desenvovlvimento local. Porto Alegre:

Medianiz.

Ferreira, L. D. (2005). Estudo analítico das variáveis da macro envolvente de um destino turistico. Revista de Estudos Politécnicos, volume II, $\mathrm{n}$ ㅇ⒋

Foddy, W. (1996). Como pergunta: teoria e prática da construção de perguntas em entrevistas e inquéritos.

Lisboa, Oeiras: Celta Editora.

França, J. A. (10 edição 1979). O Modernismo na Arte Portugues. Lisboa: Biblioteca breve, volume 43.

Galdo, E. M., \& Nielsen, J. (1996). International User Interfaces.

Gomes, A. A. (s.d.). aula_considerações - sobre-a-pesquisa.pdf. Obtido de Adobe Reader.

Gonçalves, C. (2008). Pintura Mural Alentejana: a Monumentalidade Cenográfica - o núcleo Alvito, Cuba,

Portel, Viana do Alentejo e Vidigueira. Tese de Doutoramento, Faculdade de Ciências Sociais e Huimanas da Universidade Nova de Lisboa, Lisboa.

Goode, W. e. (1977). Métodos em pesquisa social. São Paulo: Nacional.

Guareschi, P. (2000). Os Construtores da informação: meios de comunicação ideologia e ética. Petrópolis:

Vozes.

Haguenauer, C., Cunha, G., Filho, F., Araujo, M., Almeida, L., \&

Lohmann, A. (2008). Projeto Museu Virtual: Criação de Ambientes Virtuais com Recursos e Técnicas de Realidade Virtual. Revista de Realidade Virtual, 1(2).

Lynch, K. (2009). A imagem da Cidade - Arquitetura e Urbanismo. Lisboa: edições 70 .

Monteiro, P. (2013). A pintura mural no Norte Alentejo (séculos XVI a XVIII): núcleos temáticos da Serra de S. Mamede. Porto: Universidade do Porto.

Moutinho, M. C. (1990). A Função Social do Museu: a Antropologia 
e a Nova Museologia. Actas do I Colóquio Nacional de Arqueologia Industrial. I, pp. 393-396. Lisboa: Associação Portuguesa de Arqueologia Industrial.

Moutinho, M. C. (1992). O Papel da Nova Museologia ou a Museologia Social na Sociedade Contemporânea.

In O Lugar e o Papel das Ciências Sociais e Humanas (pp. 125-134). Lisboa.

Moutinho, M. C. (1993). Sobre o Conceito de Museologia Social. Cadernos de Sociomuseologia, 1, 5-7.

Moutinho, M. C. (2002). Museus \& Globalização: contributo para o

Dia Mundial dos Museus. Revista Museu, 1, 1-1.

Moutinho, M. C. (2007). Evolving Definition of Sociomuseology: Proposal for reflection. In ULHT (Ed.), XII MINOM's International Atelier. Lisbon: Cadernos de Sociomuseologia.

Muchacho, R. (2005). Museu Virtual: a importância da usabilidade na mediação entre o público e o objecto museológico. IV Congresso da SOPCOM.

Nunes, A. M. (2003). Espaços e Imagens da Justiça no Estado Novo Templos da Justiça e Arte Judiciaria.

Coimbra: Minerva.

Oliveira, S., \& Silva, B. (2007). Os Museus e a Internet: a necessidade de um agir comunicacional.

Perlin, R. (2000). Media, Art Museums and Distant Audiences. In The Virtual and the Real (p. 84).

Quivy, R. \&. (1995, 2008). Manual de Investigação em Ciências Sociais. Lisboa: Trajectos . Gardiva.

Ramos, R. J. (2015). Modernidade Inquieta - Arquitectura e identidade em construção: desdobramento de um debate em português. Porto: Edições Afrontamentos, Lda.

Reis, R., \& Barbosa, V. (2014). Museus de Sergipe: realidade aumentada e documentação na Museologia. XVI Encontro Regional de História da ANPUH-Rio: Saberes e práticas científicas.

Rodrigues, W. C. (28 de Fevereiro de 2007). page download/metodologia/metodologia_cientifica_pdf. Obtido 
de http:/www4.fct.unesp.br/docente/edu/alberto.

Serrão, V. (1992). A Pintura Proto-Barroca em Portugal (1612-1657). Coimbra: Universidade de Coimbra, Coimbra.

Silva, B. (2002). A Globalização da Educação: da escrita às comunidades de aprendizagem. Actas do 5o

Congresso da Sociedade Portuguesa de Ciências da Educação (pp. 779-788). Porto: Sociedade Portuguesa de Ciências da Educação.

Silveira, A. (2011). Sistemas Diálogos por uma experiência Museológica Dialógica em Realidade Aumentada. Porto Alegre.

Thompson, B. (1998). A mídia e a modernidade: uma teoria social da mídia. Petrópolis: Vozes.

Zuarte, S. (2011). Um Projecto: Jogos Tradicionais adaptados a portadores com deficiência, Para Plataformas de Comunicação Digital. Associação Portuguesa de Ciências da Comunicação (SOPCOM), 70 Congresso da SOPCOM: MEIOS DIGITAIS E INDUSTRIAS CRIATIVAS - OS EFEITOS E OS DESAFIOS DA GLOBALIZAÇÃO, dias 15 a 17 de Dezembro de 2011. Centro de Estudos das Tecnologias e Ciências da Comunicação, Faculdade de Letras da Universidade do Porto. 
